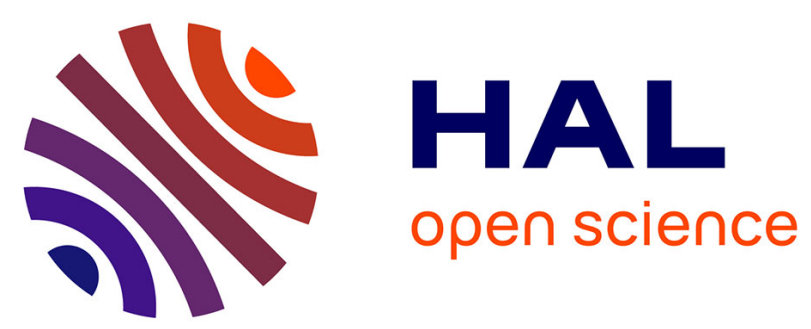

\title{
The Best of Times is Now
}

Glen Brodowsky, Neil Granitz, Beverlee Anderson

\section{- To cite this version:}

Glen Brodowsky, Neil Granitz, Beverlee Anderson. The Best of Times is Now. Time \& Society, 2008, 17 (2-3), pp.233-260. 10.1177/0961463X08093424 . hal-00571045

\section{HAL Id: hal-00571045 https://hal.science/hal-00571045}

Submitted on 1 Mar 2011

HAL is a multi-disciplinary open access archive for the deposit and dissemination of scientific research documents, whether they are published or not. The documents may come from teaching and research institutions in France or abroad, or from public or private research centers.
L'archive ouverte pluridisciplinaire HAL, est destinée au dépôt et à la diffusion de documents scientifiques de niveau recherche, publiés ou non, émanant des établissements d'enseignement et de recherche français ou étrangers, des laboratoires publics ou privés. 


\title{
Time
}

Society

\section{The Best of Times is Now A study of the gay subculture's attitudes toward time}

\section{Glen Brodowsky, Neil Granitz and Beverlee Anderson}

\begin{abstract}
Although researchers have found that cognitive temporal structures differ across cultures, few have studied the cognitive temporal structures of subcultures within them - and in a consumer behavior context. Integrating the literature on time, culture and consumer behavior, this study empirically tests for variations in time perceptions between the dominant heterosexual culture and the gay subculture. Results indicate that there may be socio-cultural elements of a subculture that produce variation in a subculture's temporal cognitive structure. Compared to heterosexuals, gays are more present-oriented. This finding is then applied to predict differences in consumer behavior. KEY WORDS cognitive temporal structure; consumer behavior; culture; gay; subculture
\end{abstract}

\section{Introduction}

Sorokin and Merton (1937) point out that nothing, including behavior, moves without time. A person's cognitive temporal structure is developed through a process firmly rooted in personal history and culture (Bergadaa, 1990; Yusua, 2006). Hofstede (1984: 260) defines culture as 'the collective programming of the mind which distinguishes the members of one human group from another'. Erez and Earley (1993: 40) view culture as a 'shared value system that results in decreased variability'. Cultures are distinguished by a shared cognitive structure 
that includes time concepts, perceptions and attitudes (Strauss and Quinn, 1998). Indeed, many researchers have found that different cultures share different cognitive temporal structures and that time concepts, perceptions and attitudes differ across cultures (Levine and Wolff, 1985; Levine, 1988, 1997; Anderson and Venkatesan, 1994; Brodowsky and Anderson, 2000; Anderson and Brodowsky, 2001; Bearden et al., 2006; Van Auken et al., 2006). People demonstrate belonging to a culture by aligning their time perceptions to those of the culture (Golden, 2002).

Social time is the shared cognitive temporal structure of a culture; it is the aspect of culture that sets the pace, the timing and the tempo of how time is lived (Levine and Wolff, 1985). It is qualitatively differentiated according to the beliefs and customs common to the group. Social time is also the dominant model of time influencing consumer behavior (Jacoby et al., 1976; Hirschman, 1987; Bergadaa, 1990). It affects when people buy products or patronize service establishments (Chintagunta and Haldar, 1998); how frequently they purchase or repurchase goods or services (Rajendran and Tellis, 1994); how long they expect things to last (Schniederjans et al., 2004); how long they are willing to wait for service (Davies and Omer, 1996; Anderson and Brodowsky, 2001); how much they will pay (Srivastava and Oza, 2006); and the times and stages of their lives when they seek and buy different products (Van Auken et al., 2006).

Within any culture, several subcultures may exist (Karahanna et al., 2005). Based on the work of Lenartowicz and Roth (2001), a subculture can be defined as a secondary group within society that exhibits a shared pattern of values which varies from the culture and impacts on the individuals that belong to it. They are segments of society that share distinguishing values, knowledge and behavior that differ and possibly conflict with the dominant culture (Chang and Chuang, 2005). Subcultures are 'worlds within the larger world of our national culture' (Komarovsky and Sargent, 1949: 143). Although many have studied cross-cultural time differences, fewer have studied how being a member of a subcultural group may influence social time concepts, perceptions and attitudes. Examples include the study of colored people's time compared to that of white people (Henry, 1965; Weis, 1997) and the time horizons of Chicanos compared to those of Anglos (Coser and Coser, 1963).

The gay segment is now widely accepted as a subculture of its own. The American Psychological Association (2006) states that 'multiculturalism, in an absolute sense, recognizes the broad scope of dimensions of race, ethnicity, language, sexual orientation, gender, age, disability, class status, education, religious/spiritual orientation, and other cultural dimensions'. If membership in a culture or subculture influences one's cognitive temporal structure, which in turn influences one's actions and behaviors, then organizations interested in targeting subculturally defined segments, such as gay consumers, should con- 
sider whether, compared to the dominant culture, subcultures have distinctive views of time that affect their consumption behavior. Many gay people allude to 'Gay Standard Time', which Everything2.com (Anonymous, 2006a) describes as a 'humorous concept used self-deprecatingly by many queers to name a stereotype that gay people - especially gay men - are unpunctual or, as those who commit this sin say, "fashionably late". However, there have been no empirical studies of whether this subcultural time zone exists. Time, as it may be uniquely experienced by gay people, has been studied primarily in terms of life stage, aging and the differences between chronological and perceptual age (Bennett and Thompson, 1991).

This study explores the relative effects of culture versus subculture as influencers of social time; it empirically tests for similarities and differences between gay and heterosexual individuals living in the United States (US) on how they view time. As members of a distinct subculture, this study asks whether gays view time differently from the dominant heterosexual culture and, if so, how these differences can be expected to affect consumer behavior. The gays and heterosexuals surveyed all live within the dominant US culture, in which heterosexuality is the dominant norm.

It is critical to research these questions for several reasons. First, previous empirical research has focused predominately on time and culture (Graham, 1981; Hall, 1983; Usunier, 1991; Anderson and Venkatesan, 1994; Brodowsky and Anderson, 2000) and, to a limited extent, on time and subculture (Coser and Coser, 1963; Henry, 1965; Weis, 1997); this analysis continues the research on time and subcultures, and positions it in a consumer behavior context. Second, as organizations continue to gear up in targeting gay consumers (Duecy, 2005; Gunther, 2006; Vence, 2006), they need guidance on how to approach this segment. This research will uncover a new area of subculturally influenced consumer behavior. Third, this study integrates time, cross-cultural, subcultural and consumer behavior literatures, as well as the literature on the gay subculture. Fourth, this research will spotlight a subculture that is often disregarded by practitioners and marketing academics (Seckler, 2004). Thus, it can spark additional interest and academic research on the gay segment.

\section{Literature Review}

The objective of this literature review is to discuss key concepts from the time and culture literatures and to explore how they may distinctly influence the time perceptions of the gay subculture and the subsequent effects on consumer behavior. The review begins with a discussion of social time and culture; a link between time orientation and consumer behavior is established. This is followed by an examination of past research on the gay subculture. Then, a look at previ- 
ously identified differences among other groups is presented in order to reflect upon potential differences between the cognitive temporal structure of gays and heterosexuals.

\section{Social time as a cultural construct}

Hirschman (1987) reviews time theories across several disciplines. While economic and social psychological disciplines focus on objective time expenditures and trade-offs, and psychological time recognizes individual subjective time experiences in relation to objective time - the sociological literature on time is identified as the discipline that explicitly recognizes time in a cultural context. Social time consists of self time and interactional time. Self time is defined as '... the types of experiences, their temporal nearness, and their spatial forms in memory' (Lewis and Weigert, 1981: 1). Self time is embedded in interactional time structures in which people synchronize their time with others (Hirschman, 1987). Both self time and interactional time are embedded in macro structures, such as culture. Thus, social time is an inter-subjective social reality that is common to a group (Zerubavel, 1982); it is a cultural construct that serves to synchronize one's time with the culture. Social time is also viewed as the dominant mode of time influencing consumer behavior (Hirschman, 1987).

An early thought leader in the study of time as a cultural construct was Edward T. Hall. In The Silent Language (1959), he introduced the monochronic (M-Time) and polychronic (P-Time) ways of handling time. M-Time is a perspective through which people view time as a linear uni-dimensional commodity; notions of doing one thing at a time, scheduling blocks of time and viewing time as money are associated with M-Time thinkers. In contrast, PTime is a relationship-oriented perspective on time. In the context of long-term relationships, P-Timers are more likely to engage in multiple activities at once. Hall demonstrated how M-Time is more closely associated with Northern Europe and America, while P-Time was associated with the Mediterranean and Middle Eastern cultures. In each successive book, Hall elaborated on these concepts. In 1983's The Dance of Life, he attempted to describe the different kinds of time through his Map of Time, which included eight distinct time types. Several schemas and elaborations that evoke Hall's concepts have been introduced (Graham, 1981; Felker-Kaufman et al., 1991; Usunier, 1991; KaufmanScarborough and Lindquist, 1999). Table 1 illustrates Hall's eight types of time and Graham's three types of time.

Empirical studies have identified specific cross-cultural differences related to temporal systems (Hall's eight types of time and Graham's three models of time). In comparing several countries, Usunier (1991) found that West Germany scored highest for monochronism while Brazil ranked highest for polychronism. In comparing Indian time to Japanese time, Nakamura (1981) demonstrates how 
TABLE 1

Hall's and Graham's types of time

\begin{tabular}{|c|c|}
\hline Time & Explanation \\
\hline \multicolumn{2}{|c|}{ Hall's eight types of time (Hall, 1983) } \\
\hline 1. Biological & $\begin{array}{l}\text { In tune with nature's cycles of } \\
\text { light and dark; natural bio-rhythms. }\end{array}$ \\
\hline
\end{tabular}

2. Physical

Time that is objectively measured based on the movement of the sun.

3. Personal

How individuals experience time based on external influences (contexts, settings, etc.) and internal influences (emotional, psychological, etc.).

4. Metaphysical Time that exists when one is cut off from time and space (i.e. precognitive experience).

\section{Sacred People are in the time; past, present and future cease to exist.}

\section{Profane The marking of time through watches and calendars.}

7a. Micropolychronic

7b. Micromonochronic

8. Sync personal involvement with and keeping in touch with people. Doing one thing at a time; time is money and it can be saved, spent and lost.
Example

American shift workers experience

problems as their bodies adjust to natural rhythms, such as the day/night cycle (Adam, 1995).

In 1600-1900, the Japanese used a sundial to mark the noon hour (Sugimoto and Swain, 1989).

In the US healthcare system, Chinese and Vietnamese immigrants find the wait time between making an appointment and seeing a doctor as intolerable; in their native countries, they are accustomed to simply walking in to see a doctor (Ngo-Metzger et al., 2003).

The Western psychological view sees dreams as resulting from past behavior. The Guajiro Indians of Northern Venezuela view dreams as prefiguring the future (Ingram, 2006).

The Hopi believe that people do not come into being but have always existed. This 'other' world exists in mythic time. In this world, animals, plants and humans understand each other (Ward, 2006).

In both the US and Iran, the initial proposed movement to daylight-saving time was met with vociferous protest by traditional, rural segments of the population (Movahedi, 1985).

Doing many things at once; stresses

Compared with monochronics (US and Finland), polychronics (Egypt and Peru) were less concerned about long download times (Rose et al., 2003).

Hall (1983) found that while speaking, Blacks and Indians gesture with both sides of their body while Whites only use one side. In the negotiation process, low context cultures (Germany, Sweden, US) and high context cultures (Hong Kong, Japan, Thailand) follow different behavioral sequences (Adair and Brett, 2005). 
TABLE 1 (cont.)

\begin{tabular}{|c|c|c|}
\hline Time & Explanation & Example \\
\hline \multicolumn{3}{|c|}{ Graham's three types of time (Graham 1981) } \\
\hline $\begin{array}{l}\text { 1. Linear } \\
\text { separable }\end{array}$ & $\begin{array}{l}\text { Related to monochronic time; } \\
\text { there is a present, past and future } \\
\text { that is separable into discrete } \\
\text { pieces. }\end{array}$ & $\begin{array}{l}\text { Compared with cultures that see time as } \\
\text { circular (expect the same future), cultures } \\
\text { that see time as linear (expect a different }\end{array}$ \\
\hline 2. Circular & $\begin{array}{l}\text { Related to polychronic time; } \\
\text { time is viewed as a circle with } \\
\text { events repeating. The future is } \\
\text { the same as the past. }\end{array}$ & $\begin{array}{l}\text { future) are more likely to adopt } \\
\text { innovations (Van Everdingen, 2003). }\end{array}$ \\
\hline $\begin{array}{l}\text { 3. Procedural } \\
\text { traditional }\end{array}$ & $\begin{array}{l}\text { Related to sacred time; it is more } \\
\text { important that a job be done right } \\
\text { than on time. The amount of time } \\
\text { spent on a job is irrelevant. }\end{array}$ & $\begin{array}{l}\text { Philips (1974) recounts how non-Indians } \\
\text { cannot obtain a specific timeframe for an } \\
\text { event that will occur on Warm Springs } \\
\text { Indian Reservation. }\end{array}$ \\
\hline
\end{tabular}

Indian time is static and unchanging while Japanese welcome fluidity. There are numerous other examples of cultural differences listed in Table 1.

Social time systems, be they monochronic, polychronic or other, have several dimensions. The dimensions of temporal systems (Lauer, 1981) include five elements: 1) periodicity, 2) tempo, 3) duration, 4) timing and 5) sequence. Periodicity details the frequency or regularity of specified activities. Tempo concerns pace or speed. The pace can be set internally by the individual or externally by task demands (Francis-Smythe and Robertson, 1999). Duration describes how long something lasts. Timing concerns the time of day, day or date for engaging in certain activities. Sequence concerns the order in which activities occur. Cross-cultural differences in temporal dimensions have been identified. For example, compared to Mexicans, Americans are more concerned with managing and saving time (Brodowsky and Anderson, 2000).

Another important dimension of social time is temporal orientations and preferences. Hornik and Zakay (1996) define temporal orientation as the relative position of past, present or future in the individual's mind. For example, time allotted to the future (versus the past) might decrease as one ages. Temporal preference refers to whether one has a past, present or future orientation. In a study comparing temporal orientations across Americans, New Zealanders and Mexicans, Americans and New Zealanders were found to fantasize about the past; all cultures thought that the best time in their lives was the present; and Mexicans daydream about the present while Americans and New Zealanders daydream about the future (Anderson and Venkatesan, 1994). East Asian countries tend to have a past orientation while Western nations tend to have a future orientation (Hall, 1976; Yau, 1988). 


\section{Time orientation and consumer behavior}

Social time, the focus of this study, has been linked to attitudes and behaviors, and in particular to consumer behavior (Hirschman, 1987). Consequently, consumer behavior researchers have developed several models of time. Manrai and Manrai (1995) present a model where cultural context influences the value system; this value system affects time attitudes. Similarly, Bergadaa (1990) introduced a model that begins with the individual's time orientation as learned from parents, family and through education; this affects a person's temporal cognitive structure which strongly influences attitudes and consumer behaviors. These two models clearly illustrate that cognitive temporal structures influence attitudes and behaviors. For example, relating temporal systems to consumer behavior, it was found that, compared with monochronic cultures (US and Finnish), polychronic cultures (Egyptian and Peruvian) were less concerned with download times (Rose et al., 2003). Thus, if gays and heterosexuals have different cognitive temporal structures, we can expect them to have different consumer behaviors.

\section{Culture and gay subculture in the US}

Culture can be defined across different hierarchical levels (Karahanna et al., 2005). The highest level is supra national (i.e. across national borders), which includes ethnic, religious, linguistic and regional associations. This is followed by national, professional, organizational and group culture. Thus, any culture can include within it several subcultures. Subcultures emerge in diverse societies where alternative shared meaning systems shape attitudes and behaviors (Plummer, 1975; Rubington and Weinberg, 1987).

As members of a distinct subculture, gays may differ in how they perceive time which, in turn, may affect their behavior. The following discussion emphasizes key variations between gays and heterosexuals in the US. The study is limited to the US because we want to compare gay subculture versus heterosexual culture within a single shared cultural system. The effects of these variations on gays' cognitive temporal structures are then explored.

Estimates of the gay and lesbian population vary from 4 per cent to 8 per cent of the US population. At 4 per cent, this is larger than the Asian American population in the US (Black et al., 2000; Gardyn, 2001). Although an increasing number of gay singles and couples are electing to have children, in the absence of children, gays have a higher disposable income (Black et al., 2002). The average household income for gays is higher at US\$61,300 compared with US\$56,900 for heterosexuals (Burnett, 2000; Kolko et al., 2003).

Gay people tend to be concentrated in urban areas. Black et al. (2000) found that 50 per cent of their gay sample lived in cities populated by 26 per cent of the 
US population. Gay couples live in neighborhoods that are older, more urban and diverse; and the residents are more educated. Nineteen per cent of both gay men and women have post-graduate degrees, compared with 14 per cent of heterosexual men and 12 per cent of heterosexual women (Kolko et al., 2003; Rothblum et al., 2004). Gays in smaller cities live disproportionately in college towns.

There are also some distinguishing characteristics related to career. Hewitt (1995) found that gays are highly concentrated in certain occupations (architects, teachers, entertainment, arts, nursing, etc.). Several possible reasons are offered: they are innately better or they experience less discrimination in these positions.

A major life event experienced by gays but not by heterosexuals is coming out. Gays are born into and grow up in the dominant heterosexual culture; they will usually subscribe to its cultural norms until acknowledging their gay identity, accepting it and revealing it to others (Rotheram-Borus and Fernandez, 1995). In the late 1970s and early 1980s, the average coming out age was 19 to 23. In 1999, a Cornell study placed the gay coming out age at 14 or 15 years old (Walker, 2001). A more recent study from San Francisco State University now places the average coming out age at 13 (Anonymous, 2006b). Thus, depending on their age, gays may spend their key formative years as part of the heterosexual culture.

Some gay people fully incorporate their gay identities across their whole lives, while others display gay or heterosexual identities at different times (Ryan and Futterman, 2001; Kates, 2002). For example, many members of the gay community may only be gay within the confines of the gay ghetto (Kates, 2000). Button (2004) identified three strategies: come out, avoid or counterfeit (portray a false straight life to some people), and found that these strategies require time and attention which could lead to lower productivity alongside social isolation, perceived aloofness and unfriendliness. Gays expend so much time and energy coming to terms with their personal identities that they have little time to explore their interests, values and abilities (Trau and Hartel, 2004; Schmidt and Nilsson, 2006).

One common threat that gays and lesbians experience is homophobia (D'Augelli and Rose, 1990; Levay and Nonas, 1997). Bowes (1996) reported astonishingly high rates of verbal and physical violence; 65 per cent of respondents suffered verbal abuse while 12 per cent had been physically assaulted. While homophobia may be declining (Stannard, 2007) and new rights have been conferred upon gay people, homophobia has, historically, made the gay community an invisible one, with secret meeting places (bars, book stores, cafes, etc.) and passwords. Again, this illustrates that many gay individuals have lived in two worlds: the straight world and the gay world.

Gays place high importance on their friendship networks (Lynch, 1987). Bell 
and Weinberg (1978) found that, compared with heterosexuals, gays were more likely to have a network of close friends.

There is a growing body of work within the gerontology literature examining issues of aging in the gay community. Hajek and Giles (2002) discussed the hyper-youth orientation. Bennett and Thompson (1991) investigated how older gay men cope with the issues of aging, given the stresses caused by the stigmatization of homosexuality in the broader society and the emphasis on youth in the gay subculture. The authors found that gay people were consistent with heterosexual people in terms of when they think middle and old age begin (41 and 63, respectively). However, the gay men in the study believed that others in their community see middle and old age beginning much earlier (39 and 54, specifically). Their findings lend some support to subcultural influences upon time concepts, at least insofar as time of life and perceptual age are concerned.

In the formative post-Stonewall years of the modern gay rights movement, the specter of premature death among gay men from AIDS may have had a sobering effect on them and their attitudes toward time. Although, in recent years, AIDS has become known less as a gay man's disease, for an entire generation of gay men, life-span horizons were severely altered. In large cities, young and middleaged gays were experiencing deaths of many of their friends and contemporaries, an experience more common among older people. Since 2001, the number of cases has been rising among gay men of all ages (Anonymous, 2007). Although the sampling procedure in Cameron and Cameron's (2005) study has come under strong criticism, their research shows that the gay male life expectancy is about 20 years shorter than the heterosexual male.

\section{The US gay subculture and differences in time perceptions}

There is no single academic study of gay time in the time, sociology or marketing literatures. Nonetheless, many studies suggest the possibility of some important differences in their shared cognitive temporal structures. As this study is exploratory, the following discussion offers preliminary thoughts on some differences that would be expected; this is based on identified differences of groups that exhibit similar characteristics to the gay population.

Szmigin and Carrigan (2001) found that the elderly preferred the present and were happy to have left the past behind, especially in terms of restrictions. The same may be true of gay people who, post-Stonewall, have won new rights and are also more visible/less restricted. Schiffman and Sherman (1991) studied elderly people and found that they recognized that they had limited time left and that they had to make choices today on how to use it; rather than viewing things as unchanging, time is being spent quickly. Some gay people who perceive that their lifetimes may be shorter (due to AIDS and HIV) may also adopt a present orientation. This present orientation may be reinforced by the fact that gay 
people are less likely to have children than heterosexual people. Gay people's orientation may mimic that of the Japanese (Nakamura, 1981), who reject the notion of an ultimate reality beyond the phenomenal world and focus on selfactualization in the present. Alternatively, Mello and Worrell (2006) found that higher education leads to greater future orientation. Thus, their higher education may predispose gay people to a future orientation.

In general, parents experience greater time pressure than non-parents (Arendell, 2000; Nomaguchi and Bianchi, 2004) and, in researching differences between men and women, consistent research has demonstrated the greater time pressure that women experience as they maintain the position of key homemaker/child caregiver while also working outside of the house (Fox and Nickols, 1983; Nickols and Fox, 1983; Manrai and Manrai, 1995; Roxburgh, 2006). Given that the majority of gay people do not have children, we would expect them to experience the opposite - less time pressure. Conversely, gay people are more likely to live in urban areas, where the pace of life, defined as the 'relative rapidity or density of experiences, meanings, perceptions and activities' (Werner et al., 1985: 14), is quicker. Fast-paced cities create an environment where time urgency and chronic activation (the tendency to remain keyed up) are the norm (Levine et al., 1989; Williams and Jobes, 1990). Thus, there are factors that could increase time pressure. Finally, higher income has been shown to allow individuals to substitute capital for time and, in particular, more leisure time (Cotte et al., 2004; Nickols and Fox, 1983); this may therefore be true of gay people who, in general, have a higher disposable income.

Gay people grow up in a heterosexual environment and then acculturate into a gay subculture. Acculturation is the process and degree to which an individual from one culture assimilates into a host culture (Hui et al., 1992). Thus, if a different cognitive temporal structure does exist for gay people, we would expect gays to adopt this structure as they acculturate from the heterosexual culture into the gay subculture. In moving from the heterosexual culture into the gay subculture, some gay people may avoid or counterfeit (Button, 2004). This leads to a double life for some, as they live straight part of the time and live gay part of the time. Francis-Smythe and Robertson (1999) found that individuals' temporal orientations and beliefs regarding temporal dimensions were dependent upon situational context. Thus, at work, people may be monochronic and at home they may be polychronic. These two worlds may also blend because gay people grow up in the heterosexual world and then, later in life, enter the gay world; they may subscribe to the heterosexual cognitive temporal structure, but have some variation to it due to differences experienced from being gay. 


\section{Methodology}

The key objective of this research was to determine whether and how members of a subculture may differ from the dominant culture in their shared cognitive temporal structures. We chose to compare the gay subculture with the dominant heterosexual culture. Thus, gay and heterosexual respondents were asked to fill out a survey instrument. The first part of the survey included a 35 -item scale measuring attitudes toward time. This scale has been used consistently by several past researchers (Anderson and Venkatesan, 1994; Venkatesan et al., 1996; Brodowsky and Anderson, 2000; Morello, 2000). Other scales were consulted but were not as complete in measuring the different time constructs (Felker-Kaufman et al., 1991; Lin and Mowen, 1994; Usunier and ValetteFlorence, 1994; Francis-Smythe and Robertson, 1999). The chosen scale includes items that measure temporal systems (e.g. 'I think of time as a straight line'), temporal dimensions ('I always like to know how long a task will take before I begin') and temporal orientations and preferences ('I spend little time thinking about the future'). Each item was measured on a five-point Likert scale anchored by strongly disagree (1) and strongly agree (5). Cronbach's alpha for this scale was .69, which is above the .60 limit deemed appropriate for exploratory research (Robinson et al., 1999). To ensure that temporal orientation was fully captured with the 35-item scale, this construct was also separately measured on a seven-item past-present-future scale (Anderson and Venkatesan, 1994). Examples include 'When I daydream, I usually daydream about the . . . past, present or future'. For temporal preferences, respondents were also asked which decade they preferred in terms of music, style and social values.

Data were collected at two locations in Southern California: at a booth set up at a Gay and Lesbian Pride Festival and among graduate and undergraduate students at a public university. A total of 671 people completed surveys. Of these, 55 per cent were male and 45 per cent were female. There was no significant difference in age between the gay and heterosexual respondents $(p=.000)$. The sample was fairly evenly split between those who were single $(48.4 \%)$ and those who were partnered (46.6\%), while only 1 per cent identified as widowed.

Care was taken to ensure diversity in both venues. People of all ages passed by the booth at the festival and surveyors visited all of the other booth vendors to enlist their participation. On campus, a broad age range was collected by including undergraduate and graduate students, most of whom were full-time working individuals. For the entire sample, 41 per cent of respondents identified as Baby Boomers (born 1946-1963), 36 per cent as Generation X (born 1964-1979) and 22 per cent as Generation Y (born 1980-1992). These proportions approximate the general population of the region in which the data were collected, according to census data. The mean age for the entire sample was 37 , with a standard deviation of 12 years. 
In terms of ethnicity, 66 per cent of the respondents identified as Caucasian, 14.7 per cent as Hispanic, 5.7 per cent as Asian American, 5.3 per cent as African American and 1.3 per cent as Native American. There was no significant difference in ethnicity between gay and heterosexual respondents.

The analysis began with a principal components analysis of the 35-item temporal attitudes scale. To ensure validity, we split the sample into two groups (Hair et al., 2005). Group I consisted of 296 respondents while Group II consisted of 284 respondents. No significant demographic differences were identified between the two groups. Principal components analysis was conducted using Group I data. With more than eight cases per item, this data set surpassed the required sample size for factor analysis (Hair et al., 2005). Then, using the data from Group II, summated scales of factor items were calculated and then compared across the gay and heterosexual respondents. To determine whether significant differences in analysis of variance (ANOVA) scores across the factors translate into differences in consumer behavior, a multivariate analysis of variance (MANOVA) was undertaken between the gay and heterosexual respondents with respect to the time-related consumer behavior questions (dependent variables). To confirm differences, cross-tabs were run between the past-present-future questions and the gay versus heterosexual respondents.

\section{Analysis and Results}

A principal components analysis using a varimax rotation was performed on the 35 -item temporal attitudes scale. Inspection of eigenvalues and the scree plot suggested an 11-factor solution explaining 58.4 per cent of the variance in the original 35 items. Each of the 11 factors had eigenvalues exceeding 1.0. An additional analysis was performed by constraining the principal components analysis to a 10 -factor solution. This resulted in a solution that explained barely 50 per cent of the variance in the original 35 items.

Following Hair et al.'s (2005) methodology, the next steps were to interpret the factors and their reliability. The 11-factor rotated solution in Table 2 is easily interpretable.

The first factor is called Time Management. Items loading on this factor relate to scheduling and planning. Reliability analysis of the four items with factor loadings greater than 0.50 yielded a coefficient alpha of 0.64 . This exceeds the suggested lower limit of a Cronbach's alpha greater than 0.60 for exploratory research (Hair et al., 2005). Factor 2, Time Pressure, contained three items about feeling pressed for time $(\alpha=0.60)$. Factor 3, Time Flies, consisted of two items related to losing track of time when having fun or talking with friends. Coefficient alpha for the two items was 0.48 ; the correlation coefficient of 0.32 $(p<.000)$ exceeded the minimum suggested inter-item correlation of 0.30 (Hair 
TABLE 2

35-item time attitude scale rotated factor solution

\begin{tabular}{|c|c|c|c|c|c|c|c|c|c|c|c|}
\hline & 1 & 2 & 3 & 4 & 5 & 6 & 7 & 8 & 9 & 10 & 11 \\
\hline I always like to know how long a task will take & .747 & & & & & & & & & & \\
\hline I always schedule and pre-plan everything & .722 & & & & & & & & & & \\
\hline I want to know the ending and beginning time & .542 & & & & & & & & & & \\
\hline Managing time is key to success & .525 & & & & & & & & & & \\
\hline \multicolumn{12}{|l|}{ If I don't complete everything, I feel frustrated } \\
\hline \multicolumn{12}{|l|}{ I do things on a regular scheduled basis } \\
\hline \multicolumn{12}{|l|}{ I try to group activities together so I can save time } \\
\hline I feel I have little control over my time & & .735 & & & & & & & & & \\
\hline I have control over my time & & -.697 & & & & & & & & & \\
\hline I feel a great amount of time pressure & & .512 & & & & & & & & & \\
\hline \multicolumn{12}{|l|}{ I would like the pace of my life to be slower } \\
\hline \multicolumn{12}{|l|}{ Never enough time to do things I enjoy } \\
\hline I like to spend time talking with friends and family & & & .695 & & & & & & & & \\
\hline When I'm enjoying myself, I lose track of time & & & .672 & & & & & & & & \\
\hline \multicolumn{12}{|l|}{ I plan each day } \\
\hline Time lost can never be regained & & & & .771 & & & & & & & \\
\hline I treat time as a scarce resource & & & & .707 & & & & & & & \\
\hline Time heals all wounds & & & & & .673 & & & & & & \\
\hline The future looks brighter than the past & & & & & .586 & & & & & & \\
\hline What I don't get done today, I can do tomorrow & & & & & .584 & & & & & & \\
\hline \multicolumn{12}{|l|}{ People used to have more time than we do today } \\
\hline I think of time as a straight line & & & & & & .779 & & & & & \\
\hline I think of time as a circle & & & & & & -.773 & & & & & \\
\hline I am very punctual & & & & & & & .835 & & & & \\
\hline No excuse for being late & & & & & & & .749 & & & & \\
\hline \multirow{2}{*}{\multicolumn{12}{|c|}{ I rarely look at a clock or watch }} \\
\hline & & & & & & & & & & & \\
\hline I like to stay on task until it is complete & & & & & & & & & .636 & & \\
\hline I frequently lose myself in what I am doing & & & & & & & & & .571 & & \\
\hline \multicolumn{12}{|l|}{ The future goes on indefinitely } \\
\hline I spend little time thinking about the past & & & & & & & & & & .701 & \\
\hline The past is more important than the future & & & & & & & & & & -.654 & \\
\hline \multicolumn{12}{|l|}{ Interruptions bother me } \\
\hline Watching TV is a waste of time & & & & & & & & & & & 639 \\
\hline People should not waste time & & & & & & & & & & & .624 \\
\hline
\end{tabular}

Factor 1: Time Management; Factor 2: Time Pressure; Factor 3: Time Flies; Factor 4: Time Scarcity; Factor 5: Infinity; Factor 6: Time Direction; Factor 7: Punctuality; Factor 8: Future; Factor 9: Focus; Factor 10: Past; Factor 11: Time Wasting. 
et al., 2005). Factor 4, Time Scarcity, consisted of two items about time being a scarce resource which, once used, could never be regained. Coefficient alpha was 0.57 , the correlation between the two items was $0.40(p<.000)$.

Factor 5, Infinity, consisted of three items about the future going on indefinitely $(\alpha=0.49)$. All inter-item correlations were significant at $p=.001$. Factor 6 , Time Direction, consisted of two oppositely signed variables concerning whether one thinks of time as a straight line or as a circle. Coefficient alpha was 0.60 with an inter-item correlation of $0.41(p<.001)$. Factor 7 , Punctuality, consisted of two items about being on time and there being no excuse for being late. Coefficient alpha was 0.66 and the inter-item correlation of the two was 0.49 $(p<.001)$.

Factor 8, Future, consisted of a single item: 'I spend little time thinking about the future'. Factor 9, Focus, consisted of two items concerning staying on task and losing track of time when completing tasks $(\alpha=0.21)$. The correlation of the two items was $0.12(p<.001)$. Factor 10 , Past, contained two concerning attitudes toward the past $(\alpha=0.33)$; the inter-item correlation was $0.20(p<.01)$. Factor 11, Time Wasting, consisted of two items about wasting time on such activities as TV $(\alpha=0.20)$. Their correlation was $0.15(p<.001)$.

Summated scales were then created by averaging the items with loadings over 0.5 on each of the factors with reliabilities exceeding the lower threshold limit of $\alpha \geq 0.60$. The items on each of these four factors - Time Management, Time Pressure, Punctuality and Time Direction - were averaged to form the summated scales to be used in the next phase of the analysis. Since reliability measures of the remaining seven factors didn't meet the 0.60 threshold, even if their inter-item correlations exceeded 0.30 for the two-item factors, these items were considered individually in the next phase of analysis.

Given that the factors were orthogonal, a series of univariate analyses of variance were performed to compare gays and heterosexuals in the holdout sample, Group II, on the summated scales. The results are shown in Table 3.

The table illustrates that, compared with heterosexual respondents, gay respondents' mean was significantly lower on the Time Pressure dimension $\left(M_{\mathrm{GAYS}}=2.69, M_{\text {HETEROSEXUALS }}=2.90, F=5.79, p<.05\right)$. Thus, gays feel less time pressure than heterosexuals. Gay respondents' mean was significantly higher on punctuality $\left(M_{\mathrm{GAYS}}=3.60, M_{\text {HETEROSEXUALS }}=3.30, F=5.76, p<.05\right)$. Thus, gays place greater importance on punctuality.

Since reliability of the other summated scales was low, the next phase of the analysis included multivariate analyses of variance to compare the two groups on the seven subscale items identified as factors. The only significant differences between gays and non gays related to the single item Factor 8. Gays were less likely to spend time thinking about the future $\left(M_{\text {GAYS }}=2.27, M_{\text {HETEROSEXUALS }}\right.$ $=2.02, F=3.42, p<.05$ ).

Next, we further investigated differences in the temporal orientation of gays 
TABLE 3

Mean scores and ANOVA results for gays versus heterosexuals across time attitude factors

\begin{tabular}{lcccc}
\hline Factor & Mean gay & Mean heterosexual & $\mathrm{F}$ & $p$ value \\
\hline Time management & 3.28 & 3.30 & 0.18 & 0.67 \\
Time pressure & 2.69 & 2.90 & 5.79 & $0.04^{*}$ \\
Punctuality & 3.60 & 3.30 & 5.76 & $0.04^{*}$ \\
Time direction & 3.00 & 3.08 & 0.10 & 0.75 \\
\hline
\end{tabular}

* Significant at .05

TABLE 4

Mean scores and ANOVA results for gays versus heterosexuals on time-orientation items

\begin{tabular}{lcccc}
\hline Statement & $\begin{array}{c}\text { Mean } \\
\text { gay }\end{array}$ & $\begin{array}{c}\text { Mean } \\
\text { heterosexual }\end{array}$ & $\mathrm{F}$ & $p$ value \\
\hline Things are/were/will be better in & 2.41 & 2.59 & 10.21 & $.001^{*}$ \\
I prefer movies about & 2.01 & 1.87 & 4.63 & .062 \\
I most like stories about & 1.67 & 1.55 & 3.30 & .070 \\
I most frequently talk about & 2.02 & 2.03 & 0.02 & .889 \\
I would prefer living in & 2.07 & 2.13 & 1.64 & .201 \\
The best time in my life is in & 2.07 & 2.14 & 1.71 & .192 \\
I almost never worry about & 1.56 & 1.44 & 2.76 & .097 \\
When I daydream, I think about & 2.34 & 2.37 & 0.23 & .631 \\
\hline
\end{tabular}

* Significant at .05

compared with heterosexuals. This analysis was conducted in two phases. First, a series of one-way ANOVAs was conducted for each of the eight items and a MANOVA was used to test the model. In the second phase, only those items for which ANOVA indicated significant differences between the two groups were then compared using the cross-tabs function to identify preferences for the three discrete time periods - past, present and future - across the two groups. The results of the analyses of variance are presented in Table 4.

The univariate analyses suggest significant differences between gays and heterosexuals in terms of when they think things are, were or will be better $\left(M_{\mathrm{GAYS}}=2.41, M_{\text {HETEROSEXUALS }}=2.59, F=10.21, p<.05\right)$. There is also marginal support for differences in terms of preferences for movies and stories about the past, present and future $\left(M_{\mathrm{GAYS}}=2.01, M_{\text {HETEROSEXUALS }}=1.87, F=4.63, p<.10\right.$ and $F=3.30, p<.10$, respectively). Hotelling's trace was calculated at .045 , 
indicating a significant model. Due to the ordinal nature of the three-item scale, cross-tabulations were then performed on these three items. The analyses showed that compared with heterosexuals, gays were more likely to think things are better in the present than in either the past or the future $\left(\chi^{2}=8.57, p<.001\right)$. Other marginal support for differences between gay and heterosexual temporal orientation appears when comparing preferences for past, present and future themes in stories and movies. Although gay respondents were more likely to enjoy stories about the present and future, their heterosexual counterparts were more likely to enjoy stories about the past $\left(\chi^{2}=5.44, p=.065\right)$.

\section{Discussion}

Several pieces of data indicate that, compared with heterosexuals, gays appear to focus more on the present; they spend little time thinking about the future and view the future as less promising. As discussed earlier, new rights won, a shortened life expectancy among gay men, the hyper-youth orientation of the gay subculture, lower likelihood of having children and the stigmatization of growing old in the gay community may contribute to this present orientation. Finally, external social pressures may also augment the more pronounced present orientation of gays. Several marketing studies have found gay people to be more affluent and more willing to spend money in the present, with 20 to 30 per cent more disposable income to spend on clothes, food, art and travel (Burnett, 2000; Gardyn, 2001; Anonymous, 2006c). Thus, marketers may be capitalizing on and reinforcing this orientation.

Compared with heterosexuals, gays were less likely to feel Time Pressure. This finding may be related to those of Nomaguchi and Bianchi (2004) and Arendell (2000) who attributed women's perception of greater Time Pressure to the higher likelihood that they were primary caregivers within families. Since they are less likely to be parents, gays may experience less time pressure. Compared with heterosexuals, gays are also more likely to say that they are punctual. This may also be related to them being less busy by having less familial responsibilities and greater leisure time. Busy people are less punctual (Ettin et al., 1987).

Despite the variation discussed earlier, there were more similarities than differences. Gays were no more likely than heterosexuals to schedule and preplan their activities, stay with tasks until they were done or get caught up and forget about time. As both live in the US culture, they both see time as a straight line; and one that, once lost, can never be regained. Similarly, they tend to agree that time should not be wasted. Unexpectedly, given the high present orientation of gays, differences on the Infinity factor (The future goes on indefinitely/Time heals all wounds) were not found. There are two possible explanations. First, neither phrase is about one's self - they are general statements (clichés) about 
the world. Second, it is possible that the present orientation of gays is precipitated by not having children and/or higher income and/or the hyper-youth orientation but not by the threat of AIDS, which lowers the expected lifespan and thus the future.

\section{Acculturation: Explaining and differences}

It is no coincidence that a distinct gay temporal system did not emerge in the research. The work of Manrai and Manrai (1995) is relevant in explaining why there are more similarities than differences. Their study demonstrated that when individuals moved from a high context culture to a dominant low context culture, the individuals integrated into the low context culture, becoming more like them in terms of temporal orientation, temporal dimensions and time priority (work versus leisure). In this case, the opposite may be proposed; when individuals move from a dominant culture to a subculture, much of the time attitudes of the dominant culture remain. Because this research studied gay Americans, their time attitudes reflected dominant heterosexual America.

Brake (1980) views subculture as being based upon the dominant culture. If, indeed, time is a strong cultural construct, then the strength of cultural time may trump any subcultural time concepts learned later in life. The duration of time that one spends in a subculture versus a culture, as well as the strength of the subculture, may also play into the relevance of the subculture's time.

Social psychology literature offers an explanation that goes beyond time spent in the culture and strength of the culture. Identity theory asserts that people possess many identities that may reinforce or conflict with one another. Commitment refers to the density of ties that come with a particular identity. The greater the commitment, the greater the chance a particular identity will be invoked in a specific situation (Stryker, 1968; Burke and Franzoi, 1988; Stryker and Burke, 2000). Thus, the more social ties gay people have with other gays, relative to ties with heterosexuals, the more likely it is that they will show variation in their cognitive temporal structures. Additionally, the density of ties with different groups can change over time. With the coming out age becoming younger (Rotheram-Borus and Fernandez, 1995; Walker, 2001; Anonymous, 2006b), it is likely that the present orientation will grow stronger. Gays will spend less of their lives in the heterosexual culture and more of their lives identifying with the gay culture. Thus, they may experience greater ties to individuals in the gay community.

Individuals show belonging to a culture by aligning their time perceptions to those of the culture (Golden, 2002); thus, the degree/motivation to belong will also play into the time acculturation. Researchers have argued that the growing movement among gays to legalize gay marriage and the increasing number of gays electing to have/adopt children is a need to be part of the mainstream 
American culture (Anderson, 2002; Perrin, 2002; Clarke, 2003; Hull, 2003; Tasker, 2005). Thus, motivation to belong may be another underlying variable in explaining similarities. This pressure/desire may counterbalance the increasing influence of coming out at a younger age and being exposed to the gay subculture earlier.

One may question why there are subcultural differences in some aspects of cognitive temporal structure but not others. Karahanna et al. (2005) presents a model of culture wherein individual behavior is a function of different cultures simultaneously; the relative influence of each person's cultures depends upon the importance of that culture in the situation. Gays do not usually shed their heterosexual identities but rather integrate the two identities (Ryan and Futterman, 2001). Some fully incorporate both identities across their whole lives, although others display different identities at different times (Kates, 2002). For example, many members of the gay community may only be gay within the confines of the gay ghetto (Kates, 2000). Thus, subcultural time attitudes may only emerge in gay situations. One would expect there to be gay time during a relevant gay event (e.g. a circuit party) and heterosexual time during a relevant heterosexual event (e.g. a corporate office party or family gathering).

The absence of dramatic differences strengthens the argument that one's cultural notions, learned early in life, persist (Lewin, 1935; Piaget, 1946). As discussed earlier, gays are likely to hold similar cognitive temporal structures to heterosexuals because gay people grow up in a heterosexual world. Thus, a key general exploratory finding is that members of a subculture who emerge from dominant cultures are likely to subscribe (to some extent) to time systems of the dominant culture.

In contrast, previous research has demonstrated that African American (Henry, 1965) and American Indian (Hall, 1983) subcultures live within the dominant American culture, yet subscribe to different time systems. Research has shown that neither of these cultures integrates into the dominant American culture (Demo and Hughes, 1990; Deyhle and Swisher, 1997; Lester, 1999; Logan, 2004). Thus, social ties, time spent and strength of the dominant culture are low. Individuals aren't born into the dominant culture and then become African American and American Indian; they are born into and live within these subcultures. Thus, subcultures that do not originate and integrate into the dominant American culture may carry the cognitive temporal structures of their traditional cultures.

\section{Time differences and consumer behavior evidence}

Previous research demonstrates that cognitive temporal structures can affect consumer behavior (Jacoby et al., 1976; Bergadaa, 1990). Thus, there are several consumer behavior implications. First, if individuals in subcultures that 
emerge from dominant cultures share the same cognitive temporal structures, then their consumer behavior in relation to time should be similar. For example, since there were no significant differences on the time management factor, one would expect both gays and heterosexuals to share similar expectations as to how long a service will last. Second, if some subcultures hold different cognitive temporal structures because they do not originate and integrate in the dominant culture, then consumer behavior may be different from the dominant culture. Thus, African American and Caucasian Americans may hold different expectations as to when a service will start. Third, socio-cultural elements distinct to a subculture and different from the dominant culture may alter the cognitive temporal structure of the culture; so marketers must be aware of the different socio-cultural elements and how they can alter time perceptions. In this case, the lower likelihood of having children may cause gays to consume a service earlier than heterosexuals.

Despite similarities between gay and heterosexual respondents' time attitudes, significant differences persist. Understanding how these identifiable differences may manifest distinct consumer behavior is useful for marketing academics and practitioners wishing to study and serve that segment.

Chen et al. (2005) demonstrated that present-oriented people prefer immediate consumption. Thus, the present orientation may lead gays to manifest a 'buy now' attitude and to not postpone purchases. Studies have shown that in many instances, gays are more likely to be early adopters and opinion leaders in terms of fashion (Cole, 2000), and are more likely to be earlier adopters of technology than heterosexuals. Gays were among the earliest adopters of Internet technology; they are also more likely to have DVRs (digital video recorders), webenabled cell-phones, and to download videos and use text-based chat. In 2003, 63 per cent of gays had made a purchase online compared with 53 per cent of heterosexuals (Kolko et al., 2003; Florida and Gates, 2004).

Present-oriented consumers are also more likely to spend time enjoying the consumption event. For example, they reject the idea of eating for convenience and enjoy spending time shopping (Chetthamrongchai and Davies, 2000). Similarly, less future-oriented individuals are greater sensation seekers and risk-takers (Robbins and Bryan, 2004). Thus, we can expect gay (versus heterosexual) individuals to be more likely to take risks and to enjoy and get lost in consumption. The evidence shows that gay men are greater risk-takers and sensation seekers (Kalichman et al., 1996; Zimbardo and Boyd, 1999). While alcohol use is at the same incidence as for the general population, drug use is up to six times higher. Circuit parties where drug and alcohol use are heavily practiced have also grown in popularity (Mansergh et al., 2001).

As gays are less likely to view the future as positive and are more likely to live in the present, they may manifest a future-is-now orientation; this may be evidenced by their gentrification of inner-city neighborhoods. Such gentrifica- 
tion patterns have shown gays and lesbians to be urban pioneers, willing to move into poor or transitional areas and transform them into the trendy areas of the present. Heterosexuals are more likely to wait until after a neighborhood has been gentrified by gays and then move into the already developed areas (Bell and Binnie, 2004). Looked at this way, gays seem to see the future potential and act in the present (present orientation), while heterosexual couples with children are more willing to wait until an area is developed (future orientation). This present orientation, 'live for today' attitude may also be manifest in gays' attraction to large, trendy cities like New York and San Francisco that not only are more likely to be ahead of the rest of the country in terms of fashions and trends, but also offer a faster pace of life and 24-hour non-stop activity.

\section{Generalizability of the findings}

A final question that arises is whether these findings would apply to gays and heterosexuals outside of the US. This is contingent upon several variables. First, how similar is the gay culture of the US to the gay culture of another country? The gay rights movement and the AIDS crisis created an internationalization of gay culture that began in the US and expanded to the modern Western rich world (Anonymous, 1996). As such, American books, films, television, magazines and fashion continue to define contemporary gay and lesbian meaning for most of the rich world (Altman, 1996). More recently, the Internet has played a role in the homogenization of the homosexual identity (Heinz et al., 2002). Thus, the more globalized the country, the more similar the findings might be.

Second, there are several socio-cultural variables that may create variation between the time attitudes and perceptions of gays and heterosexuals. For example, the prevalence of AIDS among gay men may lead to a present orientation. Thus, in countries where AIDS is not as prevalent (Japan), this present orientation may not be as strong.

Third, other cultural variables may affect this orientation. For example, gay Indians may view time differently from gay Americans because their dominant culture views time differently.

\section{Conclusions and Future Research}

The findings of the current study support what has been assumed for a long time: gays have a stronger present orientation and are less likely to think about the future than heterosexuals.

Future research should focus on several areas. First, exploratory research seems to indicate that whether the subculture emerged from the dominant culture, or was present in the dominant culture but did not integrate, may explain 
similarities and differences in time perceptions between subcultures and the dominant culture; thus, confirmatory research to understand how these two different subcultural conditions affect cognitive temporal structure is warranted. Second, this research found differences in cognitive temporal structures that may result from differences in socio-cultural determinants. Students of consumer behavior can benefit from a better understanding of the socio-cultural determinants of each of these three components and how changes to the cognitive temporal structure caused by these determinants affect consumer behavior. Third, and related to the previous research need, there is reason to believe that gay people who came of age in the 1960s, 1970s and 1980s (during the AIDS epidemic) may hold different temporal orientations than those who came of age in the 1990s and the 21st century. As the time perceptions of a subculture change, so may the consumer behavior. Thus, a longitudinal study of different cohorts may yield a better understanding of how time systems of a subculture (or culture) can change over time. Finally, the study can be expanded beyond the US.

\section{References}

Adair, W. L. and Brett, J. M. (2005) 'The Negotiation Dance: Time, Culture, and Behavioral Sequences in Negotiation', Organization Science 16(1): 33-51.

Adam, B. (1995) Timewatch: the social analysis of time. Cambridge, MA: Polity.

Altman, D. (1996) 'On Global Queering', Australian Humanities Review (6). Available at: http://www.lib.latrobe.edu.au/AHR.

American Psychological Association (2006) Guidelines on Multicultural Education, Training, Research, Practice, and Organizational Change for Psychologists. Available at: http://www.apa.org/pi/multiculturalguidelines/definition.html.

Anderson, E. A. (2002) 'Openly Gay Athletes', Gender and Society 16(6): 860-77.

Anderson, B. B. and Brodowsky, G. H. (2001) 'A Cross-cultural Study of Waiting as a Satisfaction Driver in Selected Service Encounters', The Journal of East West Business 7(1): 11-36.

Anderson, B. B. and Venkatesan, M. V. (1994) 'Temporal Dimensions of Consuming Behavior Across Cultures', in S. S. Hassan and R. D. Blackwell (eds) Global Marketing: Perspectives and Cases (Vol. 1), pp. 177-95. Fort Worth, TX: The Dryden Press.

Anonymous (1996) 'Let Them Wed', The Economist 338(7947): 13-14.

Anonymous (2006a) Gay Standard Time (GST). Available at: http://www.everything2. com/index.pl?node_id=1305764\&lastnode_id=124.

Anonymous (2006b) Average Coming Out Age Now 13, Survey Finds. Available at: http://www.gay.com/news/article.html?2006/10/11/4.

Anonymous (2006c) Affluence of Gay Market Confirmed. Available at: http://www. rainbowreferrals.com/sponsors/marketstudy.asp.

Anonymous (2007) HIV/AIDS Among Men Who Have Sex with Men. Available at: http://www.cdc.gov/hiv/topics/msm/resources/factsheets/print/msm.htm.

Arendell, T. (2000) 'Conceiving and Investigating Motherhood: The Decade's Scholarship', Journal of Marriage and the Family 62(4): 1192-207. 
Bearden, W. O., Money, R. B. and Nevins, J. L. (2006) 'A Measure of Long-TermOrientation: Development and Validation', Journal of the Academy of Marketing Science 34(3): 456-67.

Bell, D. and Binnie, J. (2004) 'Authenticating Queer Space: Citizenship, Urbanism and Governance', Urban Studies 41(9): 1807-20.

Bell, A. P. and Weinberg, M. S. (1978) Homosexualities. New York: Simon and Schuster.

Bennett, K. C. and Thompson, N. L. (1991) 'Accelerated Aging and Male Homosexuality: Australian Evidence in a Continuing Debate', in J. A. Lee (ed.) Gay Midlife and Maturity, pp. 65-75. New York: Harrington Park Press.

Bergadaa, M. M. (1990) 'The Role of Time in the Action of the Consumer', Journal of Consumer Research 17(3): 289-302.

Black, D., Gates, G., Sanders, S. and Taylor, L. (2000) 'Demographics of the Gay and Lesbian Population in the United States: Evidence from Available Systematic Data Sources', Demography 37(2): 139-54.

Black, D., Gates, G., Sanders, S. and Taylor, L. (2002) 'Why Do Gay Men Live in San Francisco?', Journal of Urban Economics 51(1): 54-76.

Bowes. J. E. (1996) 'Out of the Closet and into the Marketplace: Meeting Basic Needs in the Gay Community', Journal of Homosexuality 31(1/2): 219-44.

Brake, M. (1980) The Sociology of Youth Culture and Youth Subcultures. London: Routledge.

Brodowsky, G. H. and Anderson, B. B. (2000) 'A Cross-Cultural Study of Consumer Attitudes Toward Time', Journal of Global Marketing 13(3): 93-109.

Burke, P. J. and Franzoi, S. L. (1988) 'Studying Situations and Identities Using Experiential Sampling Methodology', American Sociological Review 53(4): 559-68.

Burnett, J. J. (2000) 'Gays: Feelings about Advertising and Media Used', Journal of Advertising Research 40(1/): 75-64.

Button, S. (2004) 'Identity Management Strategies Utilized by Lesbian and Gay Employees', Group and Organizational Management 29(4): 470-94.

Cameron, P. and Cameron, K. (2005) 'Gay Obituaries Closely Track Officially Reported Deaths from Aids', Psychological Reports 96(3): 693-97.

Chang, L. and Chuang, H. (2005) 'The Study of Subculture and Consumer Behavior: An Example of Taiwanese University Students' Consumption Culture', Journal of the American Academy of Business 7(2): 258-64.

Chen, H., Ng, S. and Rao, A. R. (2005) 'Cultural Differences in Consumer Impatience', Journal of Marketing Research 42(3): 291-301.

Chetthamrongchai, P. and Davies, G. (2000) 'Segmenting the Market for Food Shoppers Using Attitudes to Shopping and to Time', British Food Journal 102(2): 81-101.

Chintagunta, P. and Haldar, S. (1998) 'Investigating Purchase Timing Behaviour in Two Related Product Categories', Journal of Marketing Research 35(1): 43-53.

Clarke, V. (2003) 'Lesbian and Gay Marriage: Transformation or Normalization?', Feminism and Psychology 13(4): 519-29.

Cole, S. (2000) Don We Now Our Gay Apparel: Gay Men's Dress in the Twentieth Century. Gordonsville, VA: Palgrave MacMillan.

Coser, L. A. and Coser, R. L. (1963) 'Time Perspectives and Social Structure', in A. W. Gouldner and H. P. Gouldner (eds) Modern Sociology, pp. 638-50. New York: Harcourt Brace and World.

Cotte, J., Ratneshwar, S. and Mick, D. G. (2004) 'The Times of Their Lives: Phenomen- 
ological and Metaphorical Characteristics of Consumer Timestyles', Journal of Consumer Research 31(2): 333-45.

D’Augelli, A. R. and Rose, M. L. (1990) 'Homophobia in a University Community: Attitudes and Experiences of Heterosexual Freshmen', Journal of College Student Development 31(6): 484-91.

Davies, G. and Omer, O. (1996) 'Time Allocation and Marketing', Time and Society 5(2): 253-68.

Demo, D. H. and Hughes, M. (1990) 'Socialization and Racial Identity among Black Americans', Social Psychology Quarterly 53(4): 364-74.

Deyhle, D. and Swisher, K. (1997) 'Research in American Indian and Alaska Native Education: From Assimilation to Self-Determination', Review of Research in Education, 22: 113-94.

Duecy, E. (2005) 'Attracting the Gay Consumer's Dollar', Nation's Restaurant News 39(16): 1-4.

Erez, M. and Earley, C. P. (1993) Culture, Self-Identity, and Work. New York: Oxford University Press.

Ettin, M. F., Vaughan, E. and Fiedler, N. (1987) 'Managing Group Processes in NonProcess Groups: Working with the Theme-Centered Psychoeducational Group', Group 11(3): 177-92.

Felker-Kaufman, C., Lane, P. M. and Lindquist, J. D. (1991) 'Exploring More Than 24 Hours a Day: A Preliminary Investigation of Polychronic Time Use', Journal of Consumer Research 18(3): 392-401.

Fox, K. D. and Nickols, S. Y. (1983) 'The Time Crunch: Wife's Employment and Family Work', Journal of Family Issues 4(1): 61-82.

Florida, R. and Gates, G. (2003) 'Technology and Tolerance: The Importance of Diversity to High Technology Growth', Research in Urban Policy 9: 199-219.

Francis-Smythe, J. A. and Robertson, I. T. (1999) 'Time-Related Individual Differences', Time and Society 8(2): 273-92.

Gardyn, R. (2001) 'A Market Kept in the Closet', American Demographics 23(11): $36-43$.

Golden, D. (2002) 'Belonging Through Time', Time and Society 11(1): 5-24.

Graham, R. J. (1981) 'The Role of Perception of Time in Consumer Research', Journal of Consumer Research 7(4): 335-42.

Gunther, M. (2006) 'Queer Inc.', Fortune 154(12): 94-110.

Hair, J. F. Jr., Anderson, R. E., Tatham, R. L. and Black, W. C. (2005) Multivariate Data Analysis (6th edn). Upper Saddle River, NJ: Prentice Hall.

Hajek, C. and Giles, H. (2002) 'The Old Man Out: An Intergroup Analysis of Intergenerational Communication Among Gay Men', Journal of Communication 52(4): 698-714.

Hall, E. T. (1959) The Silent Language. New York: Anchor Books.

Hall, E. T. (1976) Beyond Culture. Garden City, NY: Doubleday and Company.

Hall, E. T. (1983) The Dance of Life: The Other Dimension of Time. New York: Anchor Books.

Heinz, B., Li, G., Inuzuka, A. and Zender, R. (2002) 'Under the Rainbow Flag: Wedding Global Gay Identities', International Journal of Gender and Sexuality Studies 7(2/3): 107-24.

Henry, J. (1965) 'White People's Time, Colored People's Time', Trans-Action 2(3): $31-4$. 
Hewitt, C. (1995) 'The Socioeconomic Position of Gay Men: A Review of the Evidence', American Journal of Economics and Sociology 54(4): 461-79.

Hirschman, E. C. (1987) 'Theoretical Perspectives on Time Use: Implications for Consumer Behavior Research', in E. C. Hirschman and J. N. Sheth (eds) Research in Consumer Behavior, pp. 55-81. Greenwich, CT: JAI Press.

Hofstede, G. (1984) Culture Consequences. Newbury Park, CA: SAGE.

Hornik, J. and Zakay, D. (1996) 'Psychological Time: The Case of Time and Consumer Behavior', Time and Society 5(3): 385-97.

Hui, M. K., Joy, A., Chankon, K. and Laroche, M. (1992) 'Acculturation as a Determinant of Consumer Behavior: Conceptual and Methodological Issues', in C. T. Allen (ed.) Proceedings, AMA Winter Educator's Conference, pp. 466-73. Chicago, IL: American Marketing Association.

Hull, K. E. (2003) 'The Cultural Power of Law and the Cultural Enactment of Legality: The Case of Same-Sex Marriage', Law and Social Inquiry 28(3): 629-57.

Ingram, G. (2006) Dreaming as Precognition in Lowland South America. Available at: http://www.gordoni.net/Academic/PDF/ba_thesis.pdf.

Jacoby, J., Szybillo, G. J. and Berning, C. K. (1976) 'Time and Consumer Behavior: An Interdisciplinary Overview', Journal of Consumer Behavior 2(4): 320-39.

Kalichman, S. C., Heckman, T. and Kelly, J. A. (1996) 'Sensation Seeking as an Explanation for the Association Between Substance Use and HIV-related Risky Sexual Behavior', Archives of Sexual Behavior 25(2): 141-54.

Karahanna, E., Evaristo, J. R. and Strite, M. (2005) 'Level of Culture and Individual Behavior: An Integrative Perspective', Journal of Global Information Management 13(2): 1-20.

Kates, S. (2000) 'Out of the Closet and Out on the Street: Gay Men and Their Brand Relationships', Psychology and Marketing 17(6): 493-98.

Kates, S. (2002) 'The Protean Quality of Subcultural Consumption: An Ethnographic Account of Gay Consumers', Journal of Consumer Research 29(3): 383-99.

Kaufman-Scarborough, C. and Lindquist, J. D. (1999) 'Time Management and Polychronicity: Comparisons, Contrasts and Insights for the Workplace', Journal of Managerial Psychology 14(3/4): 288-312.

Kolko, J., Gazala, M. E. and Strohm, C. Q. (2003) Gays are the Technology Early Adopters You Want. Available at: http://www.forrester.com/ER/Print/Research/Brief/ 0,1317,17004,00.html.

Komarovsky, M. and Sargent, S. S. (1949) 'Research into Subcultural Influences upon Personality', in S. S. Sargent and M. W. Smith (eds) Culture and Personality, pp.143-62. New York: Viking Press.

Lauer, R. H. (1981) Temporal Man: The Meaning and Uses of Social Time. New York: Praeger Publishers.

Lenartowicz, T. and Roth, K. (2001) 'Does Subculture within a Country Matter? A Cross-cultural Study of Motivational Domains and Business Performance in Brazil', Journal of International Business Studies 32(2): 305-25.

Lester, D. (1999) 'Native American Suicide Rates, Acculturation Stress, and Traditional Integration', Psychological Reports 84(2): 398.

Levay, S. and Nonas, E. (1997) City of Friends: A Portrait of the Gay and Lesbian Community in America. Cambridge, MA: MIT Press.

Levine, R. V. (1988) 'The Pace of Life Across Cultures', in J. E. McGrath (ed.) The Social Psychology of Time: New Perspectives, pp. 39-60. Beverly Hills, CA: SAGE. 
Levine, R. V. (1997) A Geography of Time. New York: Basic Books.

Levine, R. V., Lynch, K., Miyake, K. and Lucia, M. (1989) 'The Type A City: Coronary Heart Disease and the Pace of Life', Journal of Behavioral Medicine 12(6): 509-24.

Levine, R. V. and Wolff, E. (1985) 'Social Time: The Heartbeat of Culture', Psychology Today 19(3): 28-35.

Lewin, K. (1935) A Dynamic Theory of Personality. New York: McGraw-Hill.

Lewis, J. D. and Weigert, A. J. (1981) 'The Structure and Meaning of Social Time', Social Forces 60(2): 432-62.

Lin, X. and Mowen, J. C. (1994) 'Time Orientation and Consumer Behavior: Theoretical Scale Development', in R. Achrol and A. Mitchell (eds) Proceedings of the 1994 American Marketing Association Summer Educators' Conference, pp. 92-104. Chicago, IL: American Marketing Association.

Logan, J. R. (2004) 'Segregation of Minorities in the Metropolis: Two Decades of Change', Demography 41(1): 1-22.

Lynch, F. R. (1987) 'Non-Ghetto Gay: A Sociological Study of Suburban Homosexuals', Journal of Homosexuality 13(4): 13-42.

Manrai, L. A. and Manrai, A. K. (1995) 'Effects of Cultural Context, Gender, and Acculturation on Perceptions of Work versus Social/Leisure Time Usage', Journal of Business Research 32(2): 115-28.

Mansergh, G., Colfax, G. N., Marks, G., Rader, M., Guzman, R. and Buchbinder, S. (2001) 'The Circuit Party Men's Health Survey: Findings and Implications for Gay and Bisexual Men', American Journal of Public Health 91(6): 953-58.

Mello, Z. R. and Worrell, F. C. (2006) 'The Relationship of Time Perspective to Age, Gender, and Academic Achievement among Academically Talented Adolescents', Journal for the Education of the Gifted 29(3): 271-89.

Morello, G. (2000) 'Time Orientation Across Cultures: A Comparative Study in Italy, Cuba and Spain', in D. Caseby (ed.) Time and Management, Proceedings of the International Conference ISIDA, pp. 81-100. Palermo: ISIDA.

Movahedi, S. (1985) 'Cultural Preconceptions of Time: Can we use Operational Time to Meddle in God's Time?', Comparative Studies in Society and History 27(3): 385-400.

Nakamura, H. (1981) 'Time in Indian and Japanese Thought', in J. T. Fraser (ed.) The Voices of Time, pp. 59-77. Amherst, MA: The University of Massachusetts Press.

Ngo-Metzger, Q., Massagli, M. P., Claridge, B. R., Manocchia, M., Davis, R., Iezzoni, L. I. and Phillips, R. (2003) 'Linguistic and Cultural Barriers to Care: Perspectives of Chinese and Vietnamese Immigrants', Journal of General Internal Medicine 18(1): 44-55.

Nickols, S. Y. and Fox, K. D. (1983) 'Buying Time and Saving Time: Strategies for Managing Household Production', Journal of Consumer Research 10(2): 197-208.

Nomaguchi, K. M. and Bianchi, S. M. (2004) 'Exercise Time: Gender Differences in the Effects of Marriage, Parenthood, and Employment', Journal of Marriage and Family 66(2): 413-20.

Perrin, E. C. (2002) 'Technical Report: Coparent or Second-Parent Adoption by SameSex Parents', Pediatrics 109(2): 341-44.

Philips, S. U. (1974) 'Warm Springs 'Indian Time': How the Regulation of Participation Affects the Progression of Events', in R. Bauman and J. Scherzer (eds) Explorations in the Ethnography of Speaking, pp. 92-104. New York: Cambridge University Press.

Piaget, J. (1946) Le Developpement de la Notion de Temps chez L'Enfant [The Development of the Notion of Time in the Child]. Paris: PUF. 
Plummer, K. (1975) Sexual Stigma: An Interactionist Account. London: Routledge.

Rajendran, K. N. and Tellis, G. J. (1994) 'Contextual and Temporal Components of Reference Price', Journal of Marketing 58(1): 22-34.

Robbins, R. N. and Bryan, A. (2004) 'Relationships between Future Orientation, Impulsive Sensation Seeking and Risk Behavior Among Adjudicated Adolescents', Journal of Adolescent Research 19(4): 428-45.

Robinson, J. P., Shaver, P. R. and Wrightsman, L. (1999) Measures of Personality and Social Psychological Attitudes. San Diego, CA: Academic Press.

Rose, G. M., Evaristo, R. and Straub, D. (2003) 'Culture and Consumer Responses to Web Download Time: A Four Continent Study of Monochronism and Polychronism', IEEE Transactions on Engineering and Management 50(1): 31-44.

Rothblum, E. D., Balsam, K. F. and Mickey, R. M. (2004) 'Brothers and Sisters of Lesbians, Gay Men, and Bisexuals as a Demographic Comparison Group', The Journal of Applied Behavioral Science 40(3): 283-301.

Rotheram-Borus, M. J. and Fernandez, M. I. (1995) 'Sexual Orientation and Developmental Challenges Experienced by Gay and Lesbian Youths', Suicide and Life Threatening Behavior 25(1): 26-39.

Roxburgh, S. (2006) "“I Wish We Had More Time to Spend Together . . .”: The Distribution and Predictors of Perceived Family Time Pressures Among Married Men and Women in the Paid Labor Force', Journal of Family Issues 27(4): 529-53.

Rubington, E. and Weinberg, M. S. (1987) Deviance: The Interactionist Perspective (5th edn). New York: Macmillan.

Ryan, C. and Futterman, D. (2001) Social and Developmental Challenges for Lesbian, Gay and Bisexual Youth. Available at: http://www.findarticles.com/p/articles/mi_ qa3781/is_200104/ai_n8939927.

Schiffman, L. G. and Sherman, E. (1991) 'Value Orientation of New Age Elderly: The Coming of an Ageless Market', Journal of Business Research 22(2): 187-94.

Schmidt, C. K. and Nilsson, J. E. (2006) 'The Effects of Simultaneous Developmental Processes: Factors Relating to the Career Development of Lesbian, Gay and Bisexual Youth', The Career Development Quarterly 55(1): 22-37.

Schniederjans, M. C., Cao, Q. and Olson, J. R. (2004) 'Consumer Perceptions of Product Quality: Made in China', Quality Management Journal 11(3): 8-19.

Seckler, V. (2004) 'Targeting Gays: Affluent Market Largely Ignored', Women's Wear Daily 187(8): 8-9.

Sorokin, P. A. and Merton, R. (1937) 'Social Time: A Methodological and Functional Analysis', American Journal of Sociology 42(5): 615-29.

Srivastava. J. and Oza S. (2006) 'Effect of Response Time on Perceptions of Bargaining Outcomes', Journal of Consumer Research 33(2): 266-72.

Stannard, E. (2007) 'What's Not Said in Polite Society: Retired NBA Star's Comments Reveal Homophobia Remains', Knight Ridder Tribune Business News (18 February): 1.

Strauss, C. and Quinn, N. (1998) A Cognitive Theory of Cultural Meaning. New York: Cambridge University Press.

Stryker, S. (1968) 'Identity Salience and Role Performance', Journal of Marriage and Family 30(4): 558-64.

Stryker, S. and Burke, P. J. (2000) 'The Past, Present, and Future of an Identity Theory', Social Psychology Quarterly 63(4): 284-97.

Sugimoto, M. and Swain, D. L. (1989) Science and Culture in Traditional Japan. Tokyo: Charles E. Tuttle. 
Szmigin, I. and Carrigan, M. (2001) 'Time Consumption, and the Older Consumer: An Interpretive Study of the Cognitively Young', Psychology and Marketing 18(10): 1091-100.

Tasker, F. (2005) 'Lesbian Mothers, Gay Fathers, and their Children: A Review', Journal of Developmental and Behavioral Pediatrics 26(30): 224-40.

Trau, R. N. C. and Hartel, C. E. J. (2004) 'One Career, Two Identities: An Assessment of Gay Men's Career Trajectory', Career Development International 9(6/7): 627-37.

Usunier, J. C. G. (1991) 'Business Time Perceptions and National Cultures: A Comparative Study', Management International Review 31(3): 197-217.

Usunier, J. C. G. and Valette-Florence, P. (1994) 'Perceptual Time Patterns (“Time Styles")', Time and Society 3(2): 219-41.

Van Auken., S., Barry, T. E. and Bagozzi, R. P. (2006) 'A Cross Country Construct Validation of Cognitive Age', Journal of the Academy of Marketing Science 34(3): 439-55.

Van Everdingen, Y. (2003) 'The Effect of National Culture on the Adoption of Innovations', Marketing Letters 14(3): 217-32.

Vence, D. (2006) 'Younger GLBT Market Spells Opportunities', Marketing News 40(6): $17-18$.

Venkatesan, M. V., Schroeder, J. and Al-Weqaiyan, A. (1996) 'Time and Consumer Behavior in Different Cultures', in F. Orlando (ed.) Proceedings of the International Symposium in Celebration of the 40th Anniversary of ISIDA, pp. 27-43. Palermo: ISIDA.

Walker, T. (2001) Creating a Safe Environment for Gay and Lesbian Students Sometimes Means Starting from Scratch, Available at: http://www.tolerance.org/teach/ magazine/features.jsp? $\mathrm{p}=0$ \&is=27\&ar=291.

Ward, M. K. (2006) Timoloqinash: Incorporating Chumash Cultural Self History into the History of California. Available at: http://www.wishtoyo.org/pdf/timoloqinash-cahistory.pdf\#search=\%22\%20\%22mythic\%20time\%22\%20hopi\%22.

Weis, L. (1997) 'Thirty Years Old and I'm Allowed to Be Late: The Politics of Time at an Urban Community College', British Journal of Sociology of Education 17(3): 241-63.

Werner, C. M., Altman, I. and Oxley, D. (1985) 'Temporal Aspects of Homes: A Transactional Perspective', in I. Altman and C. M. Werner (eds) Home Environments (Vol. 8), pp.1-32. New York: Plenum.

Williams, A. S. and Jobes, P. C. (1990) 'Economic and Quality of Life Considerations in Urban-Rural Migration', Journal of Rural Studies 6(2): 187-94.

Yau, O. H. M. (1988) 'Chinese Culture Values: Their Dimensions and Marketing Implications', European Journal of Marketing 22 (5): 44-57.

Yusua, M. (2006) 'Time for Housework and Time for Oshigoto', Time and Society 15(2-3): 215-32.

Zerubavel, E. (1982) 'The Standardization of Time: A Sociohistorical Perspective', The American Journal of Sociology 88(1): 1-23.

Zimbardo, P. G. and Boyd, J. N. (1999) 'Putting Time in Perspective: A Valid Reliable Individual-differences Metric', Journal of Personality and Social Psychology 77(6): 1271-88. 
GLEN H. BRODOWSKY is Professor of Marketing at California State University, San Marcos. ADDRESS: College of Business Administration, California State University, San Marcos, Markstein Hall, 333 S, Twin Oaks Valley Road, San Marcos, CA 92096-0001, USA.

[email: glenbrod@csusm.edu]

NEIL A. GRANITZ is Professor of Marketing at California State University, Fullerton. ADDRESS: Department of Marketing, California State University, Fullerton, P.O. Box 6848, Fullerton, CA 92834-6848, USA. [email: ngranitz@fullerton.edu]

BEVERLEE B. ANDERSON is Professor of Business and Marketing at California State University, San Marcos. ADDRESS: College of Business Administration, California State University, San Marcos, Markstein Hall, 333 S, Twin Oaks Valley Road, San Marcos, CA 92096-0001, USA.

[email: banderso@csusm.edu] 